\title{
Attributional Biases Among Clinicians: A Comparison of Psychoanalysts and Behavior Therapists
}

\author{
S. Plous and Philip G. Zimbardo \\ Stanford University
}

\begin{abstract}
We assessed the attributional style of psychoanalysts, behavior therapists, and nontherapists by using a mail survey. Respondents listed causal explanations for three hypothetical problems experienced by either themselves, their friends, or their clients. Results indicated that (a) psychoanalysts gave more dispositional explanations than situational explanations, whereas the reverse was true for behavior therapists and nontherapists; (b) psychoanalysts gave psychological explanations for problems hypothetically experienced by their friends or clients, but physical explanations for the same problems hypothetically experienced by themselves; and (c) psychoanalysts holding medical degrees gave fewer psychological attributions and more physical attributions than behavior therapists or psychoanalysts with doctorate degrees.
\end{abstract}

Therapeutic treatment recommendations depend on whether a client's problems are attributed primarily to situational constraints or to the disposition of the client, an evaluation that in turn depends on a number of factors. For example, chronic clients elicit more dispositional attributions than clients seen for the first time (Snyder, Shenkel, \& Schmidt, 1976). The factor that has been of most interest to researchers, however, is the clinician's therapeutic orientation (Langer \& Abelson, 1974; Snyder, 1977). In an experiment by Langer and Abelson (1974), psychoanalysts rated an interviewee more disturbed when he was labeled a patient than when he was labeled a job applicant, whereas behavior therapists described the same interviewee as fairly well-adjusted regardless of label. Further analysis of these data showed that the ratings of maladjustment were highly related to differences in attributional style between the two orientations (Snyder, 1977). Although behavioral and psychoanalytic clinicians did not differ in their attributions for the alleged job applicant, psychoanalysts saw the alleged patient's problems as significantly more dispositional. Given the link between therapeutic attributions and treatment recommendations (Batson, 1975), the results of this research suggest that a clinician's professional orientation may strongly affect the diagnosis and treatment of psychological problems, independent of the client's actual difficulties.

The present study replicated and extended the research findings of Langer and Abelson (1974) and Snyder (1977) by adding a comparison group of nontherapists and by examining how several previously unstudied variables were related to the attributional style of practicing therapists.

\section{Method}

A brief survay was mailed to a sample of psychoanalysts and behavior therapists, requesting them to list two explanations for what could be

The authors wish to thank L. Amanda Crane, Andrew Renouf, and Robert Rich for their assistance in coding the data.

Correspondence concerning this article should be addressed to $S$. Plous, Department of Psychology, Stanford University, Stanford, California 94305 . causing each of three hypothetical problems. The two therapist groups consisted of senior authors chosen from leading behavior therapy and psychoanalytic journals. A total of 108 psychoanalysts were selected in equal numbers from American Journal of Psychoanalysis, International Journal of Psychoanalysis, and Psychoanalytic Quarterly. Similarly, 108 behavior therapists were chosen in equal numbers from Behavior $R e$ search and Therapy and Behavior Therapy. A third set of 108 surveys were presented to a nontherapist comparison group of undergraduates at the start of their first course in psychology at Stanford University. Thirty psychoanalysts, 32 behavior therapists, and 78 students completed the surveys.

The survey briefly depicted three problems: (a) certain prodromal symptoms of clinical depression, (b) a sleep disturbance involving recurrent nightmares, and (c) the acute onset and continuation of a severe headache. The problems were selected to be roughly equal to each other in severity and time of onset. Each problem was paired with one of three hypothetical actors who experienced the disturbance: the therapist filling out the questionnaire, a client of the therapist, or the therapist's closest friend of the same sex. Crossing problem types and hypothetical actors yielded a total of nine possible scenarios. These nine combinations were counterbalanced in such a way that the three scenarios in any one survey contained one example of each problem, one example of each actor, and a randomized order of presentation.

Each therapist was sent a randomly assigned permutation of the questionnaire and a stamped return envelope. The survey instructed respondents to "imagine the scenarios are true. For each one, list two likely explanations of what could be causing the problem." Therapists were also asked to indicate their highest academic degree, number of years as a therapist, sex, and major theoretical orientation (psychoanalytic, behavioral, cognitive-behavioral, humanistic, or other). The student surveys were administered in class during the first week of the term. (In these surveys, one hypothetical actor was changed from therapist's client to student's best friend of the opposite sex.)

Returned surveys were transcribed, and any remarks that identified the specific problem were removed. The six attributions contained in each survey (two explanations for each of three scenarios) were then categorized along two separate dimensions by three independent raters who were blind to the background of the respondents. The first rater evaluated the therapists' attributions, the second evaluated the students' attributions, and the third evaluated the entire pool of attributions.

First, judges classified the attributions along a physical-psychological dimension composed of four categories: (a) physical, or causes ordinar- 
Table 1

Relative Frequency of Dispositional and Situational Attributions

\begin{tabular}{|c|c|c|c|c|}
\hline \multirow[b]{2}{*}{ Respondent group } & \multirow[b]{2}{*}{$N$} & \multicolumn{3}{|c|}{ Type of attributions } \\
\hline & & $\begin{array}{l}\text { Dispositional } \\
\text { attributions }\end{array}$ & $\begin{array}{l}\text { Situational } \\
\text { or mixed } \\
\text { attributions }\end{array}$ & $\begin{array}{c}\text { Total } \\
\text { attributions } \\
\end{array}$ \\
\hline $\begin{array}{l}\text { Psychoanalysts } \\
\quad n \\
\%\end{array}$ & 30 & $\begin{array}{r}108 \\
61\end{array}$ & $\begin{array}{l}69 \\
39\end{array}$ & $\begin{array}{l}177 \\
100\end{array}$ \\
\hline $\begin{array}{l}\text { Behavior therapists } \\
n \\
\%\end{array}$ & 32 & $\begin{array}{l}86 \\
45\end{array}$ & $\begin{array}{r}103 \\
55\end{array}$ & $\begin{array}{l}189 \\
100\end{array}$ \\
\hline $\begin{array}{l}\text { Nontherapists } \\
n \\
\%\end{array}$ & 78 & $\begin{array}{r}185 \\
39\end{array}$ & $\begin{array}{r}283 \\
61\end{array}$ & $\begin{array}{l}468 \\
100\end{array}$ \\
\hline
\end{tabular}

ily considered physiological, medical, biological, neurological, or chemical (e.g., tumor); (b) psychological, or causes involving perceptions, covert or overt behavior, or environmental factors that affect these variables (e.g., interpersonal relationships); (c) mixed, or causes appropriately classified in either of the first two categories (e.g., ulcer), including cases with both physical and psychological causes (e.g., depression over cancer); or (d) other, or unusual causes not possible to assign to the above categories (e.g., fate). Second, the judges classified the responses along a situational-dispositional dimension: (a) mostly situational, in which modifying the cause of a particular problem necessitated changing the environment (e.g., work pressure); (b) mostly dispositional, in which the problem concerned an actor's bodily functions, behavior, cognition, or affect (e.g., shyness); (c) equally situational and dispositional, in which the cause could be considered equally situational and dispositional (e.g., stress without additional information) or in which both situational and dispositional causes were mentioned (e.g., depression over rejection from lover); or (d) cannot say, in which respondents failed to specify a cause or in which causes could not be categorized within our framework.

\section{Results}

In judgments of therapists' attributions, high rater agreement was found along both the physical-psychological dimension (95\% agreement versus $51 \%$ chance agreement) and the situational-dispositional dimension ( $82 \%$ agreement versus $42 \%$ chance agreement). Comparable agreement was found in ratings of students' attributions. Consequently, analyses were based on ratings by the first two judges.

Aggregating across all six survey responses, the total percentage of dispositional attributions was considerably higher for psychoanalysts than for either behavior therapists or nontherapists (see Table 1). Psychoanalysts made an average of over $15 \%$ more dispositional attributions than behavior therapists, $t(60)=2.81, p<.01$, and over $20 \%$ more than nontherapists, $t(106)=4.88, p<.001$. Neither behavior therapists and nontherapists nor psychoanalysts with medical degrees and those with doctorate degrees differed in relative frequency of dispositional attributions. ${ }^{1}$ The difference between psychoanalysts and behavior therapists prevailed for each of the three hypothetical actors (self, friend, or client).

When making attributions for hypothetical problems con- cerning themselves, psychoanalysts were significantly less likely to invoke psychological causes than either behavior therapists $(M=.97$ versus $M=1.31), t(60)=2.00, p<.05$, or nontherapists $(M=1.42), t(106)=3.03, p<.004$. Whereas $67 \%$ of the self-attributions made by behavior therapists and $71 \%$ of those made by nontherapists were rated as psychological, only $48 \%$ of those made by psychoanalysts were rated as psychological. Psychoanalysts also made significantly more psychological attributions for their clients and friends than for themselves. This trend was particularly noticeable when dispositional attributions alone were considered. Linear contrasts, using number of psychological attributions as a dependent variable, showed no difference between self-attributions and other attributions for behavior therapists, but showed a highly significant difference for psychoanalysts, $F(1,29)=5.37, p<.03$.

Finally, the two groups of therapists differed widely in their clinical training. Among those who provided this information, $97 \%$ of the behavior therapists held a doctorate degree; only $25 \%$ of the psychoanalysts held a doctorate degree, and $71 \%$ held a medical degree. Moreover, medical training was strongly associated with attributional bias of psychoanalysts. Psychoanalysts with a medical degree made fewer psychological attributions and more physical attributions than their peers with a doctorate degree. The total number of psychological attributions among psychoanalysts with a doctorate degree was one third higher than for psychoanalysts with a medical degree $(M=4.43$ versus $M=3.32$ ), $t(25)=2.63, p<.03$. This difference held true for each of the three types of actors.

\section{Discussion}

Taken together, these results indicate that the clinical task of generating explanations for problematic behavior appears to be handled differently by psychoanalysts and behavior therapists. While the psychoanalysts in our sample gave more dispositional than situational explanations, the reverse was true of behaviorally oriented therapists. Contrary to their reputation, however, behavior therapists did not invoke situational explanations of behavior more often than a comparison group of nontherapists.

An interesting pattern emerged for different kinds of dispositional attributions made by the two types of therapists. Behavior therapists showed no difference among actors in the relative proportion of psychological and physical attributions. The psychoanalysts did differentiate. They demonstrated a clear attributional bias by perceiving the problems of others as primarily psychological in origin and perceiving their own problems as primarily physical in origin.

These data suggest that psychoanalytic training may induce a bias toward making dispositional attributions and toward producing an actor/observer difference in perceiving problems of others as primarily psychological and problems of self as pri-

\footnotetext{
'No differences in attributional style were found as a function of the particular journal from which therapists of each type were selected. Whether behavior therapists described their orientation as "behavioral" or "cognitive-behavioral" also had no effect on the outcome measures. Because no differences were observed with respect to the three hypothetical problems (depression, sleep disturbance, and headache), further discussion of this factor is omitted as well.
} 
marily physical (Nisbett, Caputo, Legant, \& Marecek, 1973). In addition, medical training may predispose therapists to explain behavior problems in terms of physical etiology. These biases are unrelated to the number of years therapists have been in practice.

Bias, as used here, denotes not a falsehood but a systematic preference for particular types of explanations. Attributions made by psychoanalysts show certain biases when compared with attributions made by behavior therapists or nontherapists. This does not rule out the possibility that the psychoanalysts are correct, for example, in attributing most problems to dispositional factors. What is at issue are the differences in attributional style among psychoanalysts, other therapists, and intelligent lay persons.

Before mentioning the implications of these results for therapy and future research, their obvious limitations should be addressed. Despite our best efforts, the sample of only 62 therapists was less than optimal. While there was no reason to believe that therapists who returned the survey were different in attributional style from those who did not, this possibility cannot be ruled out. The grains of our results must therefore be seasoned with the salt of other related research.

Other constraints include the hypothetical nature of the problems depicted in the survey, all mild in severity, recent in onset, and only briefly described. It is possible, too, that the attributional biases detected using survey techniques may not be operative in actual clinical settings. The abstract task posed by paper-and-pencil survey research may miss some essential aspects of the attributional process that go on in a personal interview or therapy session.

The results of the present study have implications for clients, therapists, and researchers. For consumers of psychotherapy, the results demonstrate that the selection of a therapist may be an important factor in determining inferred etiology and rec- ommended treatment, independent of the actual problem. The therapist's orientation and training may exert a bias on the way common problems are explained, on the locus of perceived sources of change, and consequently, on the strategies utilized to effect change. For psychoanalytic therapists, the presence of an attributional bias might be interpreted as a source of concern; because they use different standards to judge themselves and their clients, an undesirable psychoanalytic distance may be created. Since there is some evidence that empathy tends to increase situational attributions and reduce actor/observer differences (cf. Regan \& Totten, 1975), attempts to reaffirm empathy as an essential ingredient in the client-therapist relationship might offer the best antidote to undesirable therapeutic biases.

\section{References}

Batson, C. D. (1975). Attribution as a mediator of bias in helping. Journal of Personality and Social Psychology, 32, 4\$5-466.

Langer, E. J., \& Abelson, R. P. (1974). A patient by any other name . . .: Clinician group difference in labeling bias. Journal of Consulting and Clinical Psychology, 42, 4-9.

Nisbett, R. E., Caputo, C., Legant, P., \& Marecek, J. (1973). Behavior as seen by the actor and as seen by the observer. Journal of Personality and Social Psychology, 27, 154-164.

Regan, D. T., \& Totten, J. (1975). Empathy and attribution: Turning actors into observers. Journal of Personality and Social Psychology. $32,850-858$.

Snyder, C. R. (1977). "A patient by any other name" revisited: Maladjustment or attributional locus of problem? Journal of Consulting and Clinical Psychology, 45, 101-103.

Snyder, C. R., Shenkel, R. J., \& Schmidt, A. (1976). Effects of role perspective and client psychiatric history on locus of problem. Journal of Consulting and Clinical Psychology, 44, 467-472.

Received December 17, 1984

Revision received August 26, 1985 